ИВАНОВ Олег Борисович - руководитель Центра урегулирования социальных конфликтов (129063, Россия, г. Москва, пр-кт Мира, 72, офис 1207; collegiamo@gmail.com)

ИЛЬИНСКАЯ Юлия Игоревна - исполнительный директор Центра урегулирования социальных конфликтов (129063, Россия, г. Москва, пр-кт Мира, 72, офис 1207; yulia.ilinskaya@gmail.com)

\title{
МЕДИАЦИЯ КАК ИННОВАЦИОННЫЙ СПОСОБ УПРАВЛЕНИЯ СОЦИАЛЬНЫМИ КОНФЛИКТАМИ: ОПЫТ ПРАКТИЧЕСКОГО ИССЛЕДОВАНИЯ
}

Аннотация. В статье на практическом опыте рассматривается возможность эффективного управления социальными конфликтами в современной России с помощью медиации. Авторы опираются на самостоятельно собранный богатый практический материал: мнения экспертов, участников социальных конфликтов, конфликтологов, государственных служащих. Делается вывод о целесообразности применения медиации как эффективного инструмента разрешения социальных конфликтов, затрагивающих большое число участников, имеющих общественный резонанс и объективно сложносоставных с точки зрения управления и разрешения.

Ключевые слова: социальные конфликты, медиация, управление конфликтами, гражданский протест, власть, социальное партнерство

O оциальные конфликты обостряются в период активных социальных изменений. Объективность этого процесса очевидна: ведь в этот момент мы наблюдаем параллельные процессы, связанные как с распадом существующих общественных институтов, так и с созданием их актуальных аналогов. И такие процессы не могут идти бесконфликтно.

Современное российское общество характеризуется целым спектром социально-экономических и политических проблем, которые проявляются во всех сферах социальной жизни, ведут к постоянному накоплению социальной напряженности. Существующие способы управления социальными конфликтами объективно не справляются со своими задачами. Ситуация требует от общественных и публично-властных институтов создания инновационной системы управления в этой сфере. Несмотря на это, вопросы социальных конфликтов в российском обществе с учетом актуальной специфики сложившихся отношений общественных и публично-властных институтов, и в т.ч. вопросы управления такими конфликтами, остаются одними из самых слабоизученных. Поэтому такое управление осуществляется почти всегда ситуативно и, как следствие, неэффективно.

Настоящая работа посвящена анализу потенциала применения медиации как инновационного способа управления социальными конфликтами и основана на эмпирическом исследовании, которое провели ее авторы. Отметим, что избранная тема является слабо изученной. Причины этого, по нашему мнению, кроются как в небольшой отечественной практике применения медиации, так и в принципиальной новизне самого этого механизма разрешения споров.

Исследование проводилось среди руководящего состава администраций муниципальных образований Московской обл. (администрации городских округов Люберцы, Дзержинский, Власиха, Клин, городского поселения Обухово Ногинского муниципального района), муниципальных учреждений Московской обл., общественных палат муниципальных образований Московской обл. и органов территориального общественного самоуправления муниципальных образований Московской обл. Общий охват респондентов, 
участвовавших в исследовании, составил 30 чел. (12 мужчин и 18 женщин). Возраст респондентов - от 27 до 53 лет, что является достаточным для репрезентативности результатов и обеспечения применимости используемых статистических методов. Все исследования были проведены в январе - марте 2018 г. Полученные таким образом данные объективно отвечают требованиям актуальности.

В качестве диагностического инструментария, с помощью которого фиксировалось отношение респондентов к конфликтным ситуациям, их умение управлять конфликтами, использовались разработанные в психологии и социологии методики: тест Томаса и анкетирование по самостоятельно подготовленному опроснику.

Тест Томаса (опросник Кеннета Томаса) является одной из самых распространенных методик диагностики поведения личности в конфликтной ситуации (или в конфликте интересов). Сам К. Томас исходил из того, что участники конфликта в первую очередь нуждаются в умении грамотно управлять им, при этом самого конфликта не следует ни избегать, ни пытаться любой ценой окончательно разрешить его. В результате им была сформулирована своего рода двухмерная модель регулирования конфликтов, одно измерение которой строится вокруг поведения личности, основанного на внимании к интересам других участников конфликта (кооперация), а второе - вокруг поведения личности, игнорирующей окружающих и ставящей защиту собственных интересов в качестве приоритетной задачи (напористость).

Всего К. Томас выделил 5 способов регулирования конфликтов:

1) соперничество (конкуренция) - стремление добиться максимальной реализации собственных интересов, в т.ч. в ущерб другой стороне;

2) приспособление - принесение собственных интересов в жертву интересам другой стороны;

3) компромисс - достижение соглашения на основе взаимных уступок обеих сторон, поиска и реализации такого варианта, который снял бы противоречие;

4) избегание - отсутствие у стороны стремления как к кооперации, так и к достижению собственных целей;

5) сотрудничество - такой способ урегулирования конфликта, при котором участники конфликтной ситуации приходят к альтернативе, полностью удовлетворяющей их интересам.

Схематично корреляция 5 способов регулирования конфликтов по К. Томасу изображена в следующей иллюстрации.

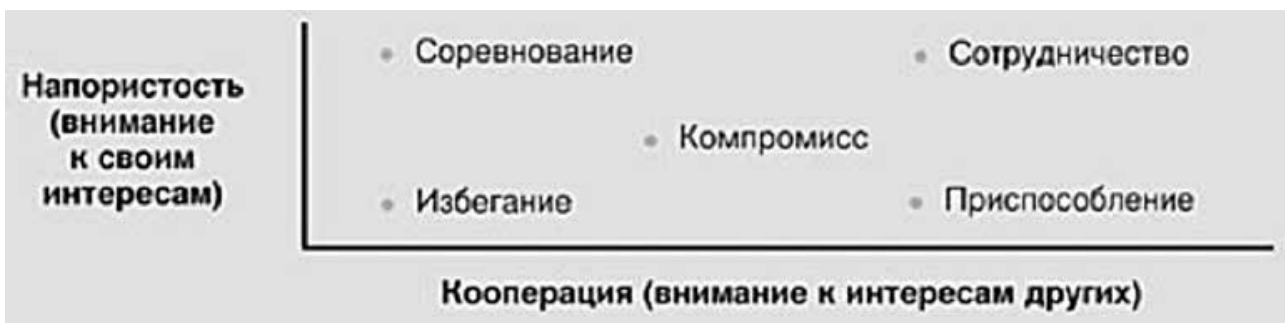

Результаты анкетирования по тесту Томаса приведены в табл. 1.

Общий результат по выборке: 1) соперничество - 156 баллов $(17,33 \%)$; 2) приспособление - 164 балла $(18,22 \%) ; 3)$ компромисс: 203 балла $(22,55 \%)$; 4) избегание - 188 баллов $(20,88 \%) ; 5)$ сотрудничество - 189 баллов $(21,00 \%)$.

Интерпретируя приведенные результаты, следует иметь в виду, что тест Томаса не только показывает типичную реакцию респондентов на кон- 
Результаты анкетирования по тесту Томаса

Таблица 1

\begin{tabular}{|l|c|c|c|c|c|c|c|c|c|c|c|c|c|c|c|}
\hline Респондент & $\mathbf{1}$ & $\mathbf{2}$ & $\mathbf{3}$ & $\mathbf{4}$ & $\mathbf{5}$ & $\mathbf{6}$ & $\mathbf{7}$ & $\mathbf{8}$ & $\mathbf{9}$ & $\mathbf{1 0}$ & $\mathbf{1 1}$ & $\mathbf{1 2}$ & $\mathbf{1 3}$ & $\mathbf{1 4}$ & $\mathbf{1 5}$ \\
\hline Соперничество & 3 & 1 & 3 & 5 & 5 & 8 & 4 & 12 & 4 & 7 & 3 & 2 & 8 & 2 & 5 \\
\hline Сотрудничество & 8 & 8 & 6 & 7 & 4 & 9 & 8 & 6 & 7 & 8 & 2 & 9 & 7 & 3 & 6 \\
\hline Компромисс & 6 & 8 & 7 & 7 & 8 & 4 & 8 & 3 & 9 & 7 & 8 & 6 & 8 & 10 & 4 \\
\hline Избегание & 9 & 7 & 4 & 7 & 7 & 5 & 5 & 4 & 7 & 5 & 9 & 5 & 4 & 8 & 7 \\
\hline Приспособление & 4 & 6 & 10 & 4 & 6 & 4 & 5 & 5 & 3 & 3 & 8 & 8 & 3 & 7 & 8 \\
\hline Респондент & $\mathbf{1 6}$ & $\mathbf{1 7}$ & $\mathbf{1 8}$ & $\mathbf{1 9}$ & $\mathbf{2 0}$ & $\mathbf{2 1}$ & $\mathbf{2 2}$ & $\mathbf{2 3}$ & $\mathbf{2 4}$ & $\mathbf{2 5}$ & $\mathbf{2 6}$ & $\mathbf{2 7}$ & $\mathbf{2 8}$ & $\mathbf{2 9}$ & $\mathbf{3 0}$ \\
\hline Соперничество & 3 & 5 & 3 & 5 & 7 & 12 & 4 & 8 & 7 & 4 & 5 & 8 & 7 & 1 & 5 \\
\hline Сотрудничество & 6 & 6 & 9 & 8 & 6 & 9 & 4 & 5 & 6 & 7 & 5 & 2 & 4 & 7 & 7 \\
\hline Компромисс & 7 & 8 & 7 & 9 & 7 & 5 & 9 & 5 & 6 & 6 & 3 & 8 & 5 & 7 & 8 \\
\hline Избегание & 8 & 7 & 7 & 5 & 6 & 1 & 7 & 7 & 8 & 5 & 9 & 6 & 7 & 8 & 4 \\
\hline Приспособление & 6 & 4 & 4 & 3 & 4 & 3 & 6 & 5 & 3 & 8 & 8 & 6 & 7 & 7 & 6 \\
\hline
\end{tabular}

фликт, но и объясняет, насколько она эффективна и целесообразна, а также дает информацию о других способах разрешения конфликтной ситуации. В этой связи представляется весьма симптоматичным, что все 5 выделенных К. Томасом способов регулирования конфликтов набрали близкое число баллов. Это позволяет сделать важнейший вывод в подтверждение выдвинутой гипотезы: муниципальные специалисты не имеют четкого представления об интересах муниципалитета в конфликте, не имеют четкого понимания того, как следует вести себя в конфликте, действуют в нем ситуативно, исходя из собственного субъективного понимания сложившихся обстоятельств. При таком положении дел, разумеется, не стоит рассчитывать на эффективное управление конфликтами. По сути, управление конфликтами на муниципальном уровне отсутствует, поскольку оно децентрализовано, хаотично и, повторимся, ситуативно.

В рамках сплошного очного анкетирования по самостоятельно подготовленному опроснику респондентам было предложено ответить на 6 вопросов, непосредственно касающихся темы настоящего исследования. Их внимание специально было обращено на то, что под конфликтными ситуациями понимаются внешние по отношению к их учреждению (органу власти) конфликты. Метод анкетирования был выбран в т.ч. в связи с тем, что он, с одной стороны, является часто используемым и понятным для респондентов, а с другой - позволяет жестко следовать намеченному исследовательскому плану, т.к. процедура «вопрос - ответ» является строго регламентированной и существенно минимизирует риски соответствующего искажения искомой информации. При этом важной особенностью анкетирования выступает анонимность исследования (личность респондента не фиксируется), что также повышает уровень его лояльности к исследованию и, следовательно, уровень объективности предоставляемой им исследователю информации на заданную тематику.

Использованный в рамках анкетирования опросный лист с вариантами ответов приведен ниже. 


\begin{tabular}{|c|c|}
\hline $\begin{array}{l}\text { Как часто вам приходится } \\
\text { сталкиваться с конфликт- } \\
\text { ными ситуациями? }\end{array}$ & $\begin{array}{l}\text { Часто и очень часто } \\
\text { Не очень часто } \\
\text { Редко }\end{array}$ \\
\hline $\begin{array}{l}\text { Конфликты в какой отрасли } \\
\text { приходится разрешать } \\
\text { наиболее часто? }\end{array}$ & $\begin{array}{l}\text { В сфере ЖКХ } \\
\text { В сфере медицины } \\
\text { В сфере образования } \\
\text { В сфере благоустройства }\end{array}$ \\
\hline $\begin{array}{l}\text { Какие способы разрешения } \\
\text { конфликтов вы используете? }\end{array}$ & $\begin{array}{l}\text { Встречи между конфликтующими сторонами, } \\
\text { переговоры, нахождение компромисса } \\
\text { Разъяснение правовых особенностей, статуса, порядка } \\
\text { правового решения вопроса } \\
\text { Обращение в правоохранительные и судебные органы }\end{array}$ \\
\hline $\begin{array}{l}\text { Как вы воспринимаете } \\
\text { конфликтные ситуации? }\end{array}$ & $\begin{array}{l}\text { Как неотъемлемую часть работы } \\
\text { Как особенный опыт } \\
\text { Раздражительно }\end{array}$ \\
\hline $\begin{array}{l}\text { Какие навыки кажутся вам } \\
\text { полезными для разрешения } \\
\text { конфликтов? }\end{array}$ & $\begin{array}{l}\text { Специальные знания } \\
\text { Стрессоустойчивость } \\
\text { Личный авторитет } \\
\text { Самообладание } \\
\text { Коммуникабельность }\end{array}$ \\
\hline $\begin{array}{l}\text { Было бы полезным для } \\
\text { вас пройти обучение } \\
\text { по конструктивной } \\
\text { коммуникации в } \\
\text { конфликтной ситуации? }\end{array}$ & $\begin{array}{l}\text { Да, было бы полезно } \\
\text { Нет, это не помогло бы мне в моей деятельности } \\
\text { Я уже прошел такое обучение }\end{array}$ \\
\hline
\end{tabular}

Решение провести исследование именно среди этой категории респондентов (выборки) обосновано следующим предположением (гипотезой). Именно эти специалисты в силу своего максимального приближения к местным жителям и местной (в т.ч. конфликтной) проблематике чаще всего являются участниками, субъектами и модераторами конфликтов, в т.ч. градостроительных, и именно от их умения грамотно управлять конфликтом на начальной стадии во многом зависит его динамика и дальнейшее развитие. При этом особенность организации работы с конфликтами на муниципальном уровне как в Подмосковье, так и в целом по России состоит в том, что в муниципальных органах власти и управления отсутствуют профессиональные специалисты, обладающие необходимой компетенцией для эффективного управления конфликтами, отсутствуют соответствующие штатные единицы, соответствующая работа выстроена через сотрудников отделов по работе с населением или аналогичных структурных подразделений, которые не являются специалистами в вопросах управления конфликтами. Данные, полученные в результате исследования, должны доказать или опровергнуть указанную гипотезу и, при необходимости, помочь сформулировать конкретные предложения по оптимизации соответствующих управленческих процессов.

Респондентам в порядке анкетирования было предложено ответить на 6 вопросов, непосредственно касающихся темы настоящего исследования. Респондентам специально разъяснили, что под конфликтными ситуациями понимаются внешние по отношению к их учреждению (органу власти) конфликты. Результаты анкетирования приведены в табл. 2.

Полученные в результате этого опроса данные позволяют сделать несколько важных выводов.

Во-первых, подавляющее большинство опрошенных (почти 77\%) констатировали, что сталкиваются с конфликтами часто и очень часто и отдают себе 
Таблица 2

Результаты анкетирования по самостоятельно подготовленному опроснику

\begin{tabular}{|c|c|}
\hline Формулировка вопроса & Распределение ответов \\
\hline $\begin{array}{l}\text { Как часто вам приходится сталкиваться } \\
\text { с конфликтными ситуациями? }\end{array}$ & $\begin{array}{l}\text { Часто и очень часто - } 76,66 \% \\
\text { Не очень часто - } 16,66 \% \\
\text { Редко }-6,68 \%\end{array}$ \\
\hline $\begin{array}{l}\text { Конфликты в какой отрасли } \\
\text { приходится разрешать наиболее часто? }\end{array}$ & $\begin{array}{l}\text { В сфере ЖКХ - 53,33\% } \\
\text { В сфере медицины - 23,33\% } \\
\text { В сфере образования - 16,66\% } \\
\text { В сфере благоустройства }-6,68 \% \\
\end{array}$ \\
\hline $\begin{array}{l}\text { Какие способы разрешения } \\
\text { конфликтов вы используете? }\end{array}$ & $\begin{array}{l}\text { Встречи между конфликтующими сторонами, } \\
\text { переговоры, нахождение компромисса } \\
\text { - 83,33\% } \\
\text { Разъяснение правовых особенностей, статуса, } \\
\text { порядка правового решения вопроса - } 13,33 \% \\
\text { Обращение в правоохранительные и судебные } \\
\text { органы - 3,34\% }\end{array}$ \\
\hline $\begin{array}{l}\text { Как вы воспринимаете конфликтные } \\
\text { ситуации? }\end{array}$ & $\begin{array}{l}\text { Как неотъемлемую часть работы - 76,66\% } \\
\text { Как особенный опыт - 6,66\% } \\
\text { Раздражительно - } 16,68 \%\end{array}$ \\
\hline $\begin{array}{l}\text { Какие навыки кажутся вам полезными } \\
\text { для разрешения конфликтов? }\end{array}$ & $\begin{array}{l}\text { Специальные знания }-40,00 \% \\
\text { Стрессоустойчивость }-23,33 \% \\
\text { Личный авторитет }-16,67 \% \\
\text { Самообладание }-10,00 \% \\
\text { Коммуникабельность }-10,00 \%\end{array}$ \\
\hline $\begin{array}{l}\text { Было бы полезным для вас пройти } \\
\text { обучение по конструктивной } \\
\text { коммуникации в конфликтной } \\
\text { ситуации? }\end{array}$ & $\begin{array}{l}\text { Да, было бы полезно - } 90,00 \% \\
\text { Нет, это не помогло бы мне в моей } \\
\text { деятельности - } 0,00 \% \\
\text { Я уже прошел такое обучение }-10,00 \%\end{array}$ \\
\hline
\end{tabular}

отчет в том, что участие в урегулировании конфликтов является неотъемлемой частью их работы (также почти 77\%). Это обстоятельство позволяет нам сделать обоснованный вывод о высоком уровне конфликтности, который присущ современному российскому обществу. Как было показано выше, большая часть этих конфликтов происходит именно на местном, локальном, муниципальном уровне и так или иначе затрагивает местные власти, которые наиболее приближены к локальному сообществу. С другой стороны, современная российская действительность имеет ярко выраженную тенденцию к сокращению числа вопросов, которые передаются для решения «вниз», на муниципальный уровень, с одновременным аппаратным усилением региональных органов власти. С учетом объективной оторванности (особенно в крупных по территории и населению регионах, таких как, например, Подмосковье) региональных органов власти от местной специфики и местных проблем, а также с учетом фактического отсутствия действенных механизмов обратной связи «региональная власть - местное сообщество» эта тенденция вполне может существенно усложнить социально-экономическую ситуацию и в значительной мере способствовать накоплению ее негативного потенциала.

Во-вторых, большинство респондентов отметили, что их участие в конфликтных ситуациях сводится к организации встреч между конфликтующими сторонами, переговорам и поиску компромисса. С одной стороны, все эти традиционные техники разрешения конфликтов обладают известной эффективностью. Однако следует учитывать, что в данном случае респондентами выступают представители органов муниципальной власти и муниципальных учреждений, 
т.е. структур, обладающих публично-властными полномочиями в той или иной сфере. И в этой связи использование переговорного процесса как основного механизма урегулирования социальных конфликтов может объясняться в т.ч. и уже упомянутым отсутствием реальных властных полномочий по наиболее конфликтным вопросам, которое таким образом маскируется, и отсутствием специальных знаний и компетенций в вопросах управления конфликтами, которые превращают реальный поиск компромисса в «забалтывание» конфликта и его перевод в максимально латентную стадию. Отчасти последнюю мысль иллюстрируют и подтверждают и данные настоящего анкетирования: так, эффективность применения тех же переговоров и поиска компромисса без специальных знаний и обучения специальным методикам (в т.ч. медиации как инновационной методике урегулирования конфликтов) самими респондентами признается невысокой, а наличие специальных знаний является важнейшим навыком, требующимся для урегулирования конфликтов (эту позицию поддерживают $40 \%$ респондентов). Более того, $90 \%$ опрошенных заявили, что прохождение обучения по конструктивной коммуникации в конфликтной ситуации было бы полезным $(90 \%)$.

Отсутствие специальных знаний среди муниципальных специалистов, работающих в конфликтной сфере, является, в свою очередь, одним из объяснений результатов, полученных по опроснику Томаса. В то же время при анализе соответствующих данных необходимо учитывать следующий общеизвестный недостаток анкетирования как методики, который выражается в объективном влиянии на результаты социальной желательности, при которой часть респондентов могут давать ответы, не адекватные их истинным убеждениям и ценностям.

В заключение отметим, что в последнее время в России наблюдается очевидный рост интереса именно к инновационным, внесудебным способам разрешения социальных конфликтов. Пока он не носит качественного характера, но это, по мнению авторов, вопрос времени и изменения отношения к социальным конфликтам со стороны властных структур, которые в настоящее время склонны пытаться «разрешать» социальные конфликты путем пропагандистского и административного выхолащивания их сути, а также с помощью иных агрессивных методик. Очевидно, что регулирование разрешения социальных конфликтов требует современных подходов, основанных на адекватном развитии специализированных институтов. Так, например, представляется правильным на законодательном уровне прописать обязанность специалистов из числа профессиональных конфликтологов, социальных психологов, социальных медиаторов «сопровождать» каждый существенный социальный конфликт.

Что касается возможности и эффективности применения медиации при разрешении социальных конфликтов, то анализ проведенных в рамках настоящей работы исследований, в т.ч. интерпретация данных, полученных в ходе психологических исследований (тест Томаса, анкетирование), показал потенциальную готовность этой сферы к ее внедрению. В то же время субъекты социальных конфликтов объективно слабо информированы о возможности применения медиации как такого способа. Относительно небольшая практика использования медиативных процедур в сфере разрешения социальных конфликтов приводит к тому, что субъекты конфликтов склонны недоверчиво реагировать на саму возможность использования медиации. В то же время и отторжения идеи использования медиации зафиксировано не было [Иванов, Ильинская 2017: 8].

Безусловно, не стоит заниматься изобретением методик, позволяющих полностью исключить социальные конфликты. Необходимо работать в другом направлении, а именно разрабатывать и реализовывать механизмы, снижающие рост напряженности между групповыми и индивидуальными интересами 
в сложном современном социуме [Левчук 2013: 182]. Еще одной проблемой видится недостаточная развитость механизмов коммуникации между субъектами социальных конфликтов. Определяющую роль здесь играет открытость власти, наличие ресурсов и технологий для такой коммуникации.

Изложенное в полной мере соответствует принципам работы медиаторов, которые закреплены в российском законодательстве: добровольность участия в процедуре медиации, конфиденциальность, равноправие сторон, беспристрастность (нейтральность) медиаторов, принцип сотрудничества, открытость, взаимоуважение, ответственность.

\title{
Список литературы
}

Иванов О.Б. Ильинская Ю.И. 2017. Медиация в градостроительных конфликтах. - Урбанистика. № 2. С. 1-10.

Левчук П.Н. 2013. Вопросы достижения политической стабильности в условиях функционирования городских коалиций роста. - Научные ведомости Белгородского государственного университета. Сер. История. Политология. № 15(158). C. 180-185.

IVANOV Oleg Borisovich, Head of the Center for Settlement of Social Conflicts (of. 1207, 72 Mira Ave, Moscow, Russia, 129063; collegiamo@gmail.com)

IL'INSKAYA Yulia Igorevna, Executive Director of the Center for Settlement of Social Conflicts (of. 1207, 72 Mira Ave, Moscow, Russia, 129063; yulia.ilinskaya@gmail.com)

\section{MEDIATION AS AN INNOVATIVE WAY TO MANAGE SOCIAL CONFLICTS: AN EXPERIENCE OF PRACTICAL RESEARCH}

\begin{abstract}
In the Russian society, the number of citizens expressing dissatisfaction with the forms of government response to social demands is growing. Conflict state of society is the result of the perception of the surrounding social environment. The article examines the possibility of effective management of social conflicts in modern Russia through mediation. The authors rely on independently collected rich practical material: opinions of experts, participants in social conflicts, conflictologists, and civil servants. The authors consider the specifics of social conflicts in modern Russia and point to the need to develop and use innovative methods that correspond to the current level of the development of society, which would effectively manage social conflicts. The contradictions formed in the system of relations between the state and civil society, the peculiarities of problem interactions and the transfer of conflict potential into a positive-functional channel are revealed. The authors conclude about the expediency and potential effectiveness of using the tools offered by mediation to achieve the stated goals.
\end{abstract}

Keywords: social conflicts, mediation, conflict management, civil protest, power, social partnership 